\title{
The Small Heat-Shock Proteins HSPB2 and HSPB3 Form Well-defined Heterooligomers in a Unique 3 to 1 Subunit Ratio
}

\author{
John den Engelsman ${ }^{1}$, Sandor Boros ${ }^{1}$, Patricia Y. W. Dankers ${ }^{1}$, \\ Bram Kamps ${ }^{1}$, Wilma T. Vree Egberts ${ }^{1}$, Csaba S. Böde ${ }^{2}$, \\ Laura A. Lane ${ }^{3}$, J. Andrew Aquilina ${ }^{4}$, Justin L. P. Benesch ${ }^{3}$, \\ Carol V. Robinson ${ }^{3}$, Wilfried W. de Jong ${ }^{1}$ \\ and Wilbert C. Boelens ${ }^{1 *}$
}

\author{
${ }^{1}$ Department of Biomolecular \\ Chemistry 271, Nijmegen \\ Center for Molecular Life \\ Sciences, Institute for Molecules \\ and Materials, Radboud \\ University, P.O. Box 9101, \\ 6500 HB Nijmegen, \\ The Netherlands
}

${ }^{2}$ Department of Biophysics and Radiation Biology, Semmelweis University, P.O. Box 263, Budapest, Hungary

${ }^{3}$ Department of Chemistry, University of Cambridge, Lensfield Road, Cambridge, UK

${ }^{4}$ School of Biological Sciences, University of Wollongong, Northfields Avenue, Wollongong, Australia

Received 17 July 2009; received in revised form 21 August 2009; accepted 21 August 2009 Available online 26 August 2009

Edited by M. Moody

\begin{abstract}
Various mammalian small heat-shock proteins (sHSPs) can interact with one another to form large polydisperse assemblies. In muscle cells, HSPB2/ MKBP (myotonic dystrophy protein kinase-binding protein) and HSPB3 have been shown to form an independent complex. To date, the biochemical properties of this complex have not been thoroughly characterized. In this study, we show that recombinant HSPB2 and HSPB3 can be successfully purified from Escherichia coli cells co-expressing both proteins. Nanoelectrospray ionization mass spectrometry and sedimentation velocity analytical ultracentrifugation analysis showed that HSPB2/B3 forms a series of well defined hetero-oligomers, consisting of 4, 8, 12, 16, 20 and 24 subunits, each maintaining a strict 3:1 HSPB2/HSPB3 subunit ratio. These complexes are thermally stable up to $40^{\circ} \mathrm{C}$, as determined by far-UV circular dichroism spectroscopy. Surprisingly, HSPB2/B3 exerted a poor chaperone-like and thermoprotective activity, which is likely related to the low surface hydrophobicity, as revealed by its interaction with the hydrophobic probe 1-anilino-8-naphthalenesulfonic acid. Co-immunoprecipitation experiments demonstrated that the HSPB2/B3 oligomer cannot interact with HSP20, HSP27 or $\alpha$ B-crystallin, whereas the homomeric form of HSPB2, thus not in complex with HSPB3, could associate efficiently with HSP20. Taken altogether, this study provides evidence that, despite the high level of sequence homology within the sHSP family the biochemical properties of the HSPB2/B3 complex are distinctly different from those of other sHSPs, indicating that the HSPB2/B3 assembly is likely to possess cellular functions other than those of its family members.
\end{abstract}

(C) 2009 Elsevier Ltd. All rights reserved.

Keywords: molecular chaperones; crystallin; small heat-shock protein; heterooligomers; MKBP

\footnotetext{
${ }^{*}$ Corresponding author. E-mail address: w.boelens@ncmls.ru.nl.

Abbreviations used: sHSP, small heat-shock protein; $\mathrm{MKBP}$, myotonic dystrophy protein kinase-binding protein; SEC, size-exclusion chromatography; MALLS, multi-angle laser light-scattering; nanoESI-MS, nanoelectrospray ionization mass spectrometry; CS, citrate synthase; ANS, 1-anilino-8-naphthalenesulfonic acid.
}

\section{Introduction}

Small heat-shock proteins (sHSPs) are molecular chaperones characterized by the presence of a conserved sequence of about 80-100 residues, referred to as the $\alpha$-crystallin domain (for recent reviews see Refs. [1-3]). This domain forms the Cterminal part of the protein, and is folded into a $\beta$ sandwich structure. ${ }^{4-6}$ The N-terminal part is more variable in both length and sequence, and largely 
determines the association properties of the homoor heteromeric oligomers of sHSPs. $^{7-9}$ The $\alpha-$ crystallin domain generally has a short and flexible C-terminal extension that modulates the chaperone-like activity, possessed by most sHSPs. ${ }^{10-12}$ sHSPs can form macromolecular associations up to $800 \mathrm{kDa}$, and the readily dissociating subunits can exchange freely between these large assemblies. In vitro, sHSPs typically display chaperone-like activities, measured by their ability to protect model substrates from thermally or chemically induced aggregation. ${ }^{13,14}$ In vivo, different sHSPs are implicated in an array of cellular processes, varying from muscle contraction, cell migration and cell survival to controlling redox state and apoptosis (for reviews see Refs. [15-17]).

In human, 10 members of the sHSP family have been recognized, formally designated as HSPB1HSPB10. ${ }^{18,19}$ While several members of the family have been studied extensively, only limited information is available for HSPB2 (MKBP) and HSPB3. ${ }^{20}$ HSPB2 and HSPB3 are expressed mainly in heart and skeletal muscle. ${ }^{21,22}$ HSPB2 and HSPB3 have been identified in muscle extract as a heterooligomer with an apparent molecular mass of $150 \mathrm{kDa}$. This sHSP complex has a more defined size than those formed by HSP27, $\alpha$ B-crystallin or HSP20, as the size of these latter complexes varies between 40 and $500 \mathrm{kDa}{ }^{21}$ HSPB2 was initially discovered as a specific binding partner for myotonic dystrophy protein kinase (DMPK), hence its alternative name MKBP (DMPK-binding protein). ${ }^{23}$ This interaction enhances the kinase activity of DMPK and protects it from heat-induced inactivation. $^{23}$ Association of HSPB2 with the outer membrane of mitochondria suggests a role in mitochondrial function. ${ }^{24,25}$ This might be related to the observed role of HSPB2 in the protection of the energy reserve; mice lacking HSPB2 had a higher rate of ATP loss during ischemic stress, and the recovery of the energy level after ischemia was slower. ${ }^{26}$ HSPB2 has been implicated in the pathogenesis of diseases. In myotonic dystrophy, the diseased muscles with reduced DMPK levels show an increased expression of HSPB2. ${ }^{23}$ Furthermore, HSPB2 can associate with the A $\beta$-containing plaques in Alzheimer's disease brains, possibly preventing the pathogenic action of $A \beta .27,28$

Much less is known about HSPB3. Based on sequence prediction, HSPB3 was found to be the smallest member of the sHSP family, with a monomeric mass of $17 \mathrm{kDa} .{ }^{29}$ A remarkable feature of HSPB3 is the lack of the C-terminal extension. ${ }^{29}$ In heart extracts, it interacts exclusively with HSPB2, ${ }^{21}$ and upon proteasomal inhibition, ectopically overexpressed HSPB3 can translocate to the cytoskeleton in cultured rat cardiac H9C2 cells. ${ }^{30}$ Like HSPB2, the expression levels of HSPB3 are not upregulated upon heat-shock. ${ }^{21}$

Our goal in this study was twofold: (1) to establish the stoichiometry of the oligomeric assembly of HSPB2/B3; and (2) to characterize the biochemical properties of the complex. Here, we show that
HSPB2 and HSPB3 form a series of complexes that are actually assemblies of tetramers with an HSPB2/ HSPB3 subunit ratio of 3:1. These oligomers were found to have poor chaperone and thermoprotective activities and are unable to interact with other sHSPs, such as HSP20, HSP27 and $\alpha$ B-crystallin.

\section{Results}

\section{HSPB2 together with HSPB3 forms heterooligomeric complexes}

Initially, attempts were made to express and purify HSPB2 and HSPB3 separately in order to study their properties and to characterize the HSPB2/B3 complex. Although the separate expression level of each protein was adequate, purification and stability proved to be unsatisfactory under a variety of conditions. Co-expression of HSPB2 with HSPB3 allowed formation of the complex in Escherichia coli and HSPB2/B3 was purified from the extract of these cells by ion-exchange chromatography. In the first DEAE step, HSPB2 eluted at low concentrations of salt together with HSPB3 in a certain ratio. However at higher salt concentrations, HSPB2 eluted mainly without HSPB3 (Fig. 1a), indicating that $E$. coli expressed an excess of HSPB2 compared to HSPB3. Unfortunately, HSPB2 was soluble only in a diluted form, as it started to

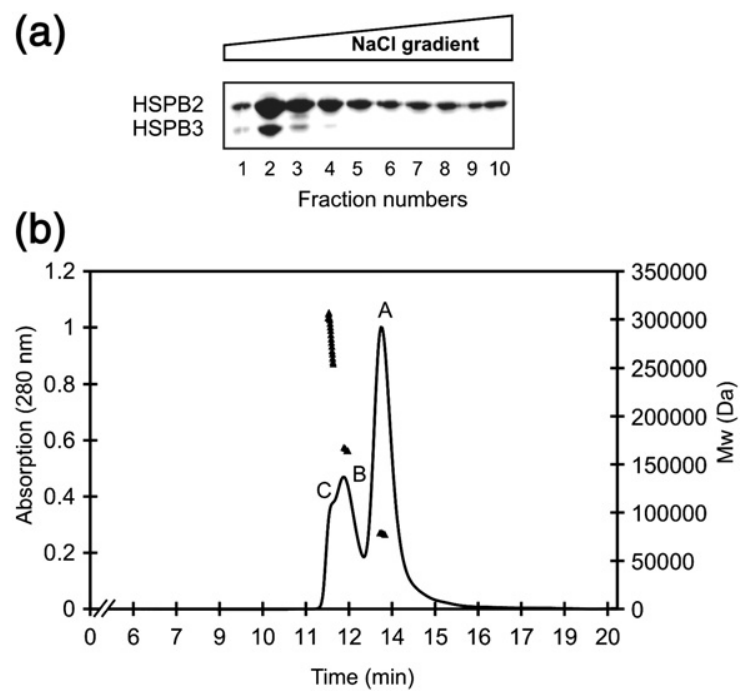

Fig. 1. Separation of HSPB2/B3. a, A lysate of E. coli cells co-expressing HSPB2 and HSPB3 was separated on a DEAE column with a $\mathrm{NaCl}$ gradient. Peak samples were collected and subjected to SDS-PAGE and stained with Coomassie brilliant blue (CBB). b, Elution pattern of purified HSPB2/B3 on a TSK-Gel3000SW column was determined by measurement of absorption at $280 \mathrm{~nm}$ (lefthand axis) in combination with continuous MALLS measurements converted to molecular masses in Da (right-hand axis). HSPB2/B3 eluted as relatively sharp peaks $\mathrm{A}$ and $\mathrm{B}$ at a mass of $78 \mathrm{kDa}$ and $166 \mathrm{kDa}$, respectively, and a front peak $C$, containing multiple complexes with increasing mass. 
precipitate at concentrations greater than $0.1 \mathrm{mg} /$ $\mathrm{ml}$, and the biochemical properties of HSPB2 on its own could not be analyzed. Fractions containing both HSPB2 and HSPB3 were pooled and further purified on a Source $\mathrm{Q}$ column and concentrated in $20 \mathrm{mM}$ phosphate buffer $\mathrm{pH} 7.5$ with $100 \mathrm{mM} \mathrm{NaCl}$ and $2 \mathrm{mM}$ EDTA to a concentration of $15 \mathrm{mg} / \mathrm{mL}$ $(0.77 \mathrm{mM})$. This solution was subsequently diluted to a final concentration of $1 \mathrm{mg} / \mathrm{mL}$ and analyzed by size-exclusion chromatography coupled with multi-angle laser light-scattering (SEC-MALLS). HSPB2 and HSPB3 appeared as three peaks in the chromatogram; a major peak $\mathrm{A}$ and a smaller peak
B, which was poorly separated from the third peak C (Fig. 1b). On the basis of the MALLS measurements, the molecular masses of the complexes in peaks $\mathrm{A}$ and $\mathrm{B}$ were calculated as $78 \mathrm{kDa}$ and 166 kDa, respectively. Peak C contained several complexes with masses in the range 250 -to $300 \mathrm{kDa}$.

\section{HSPB2/B3 forms hetero-oligomeric complexes with a fixed subunit ratio}

To further characterize the HSPB2 and HSPB3 oligomers, the complexes were analyzed by nanoelectrospray ionization mass spectrometry (nano-ESI-
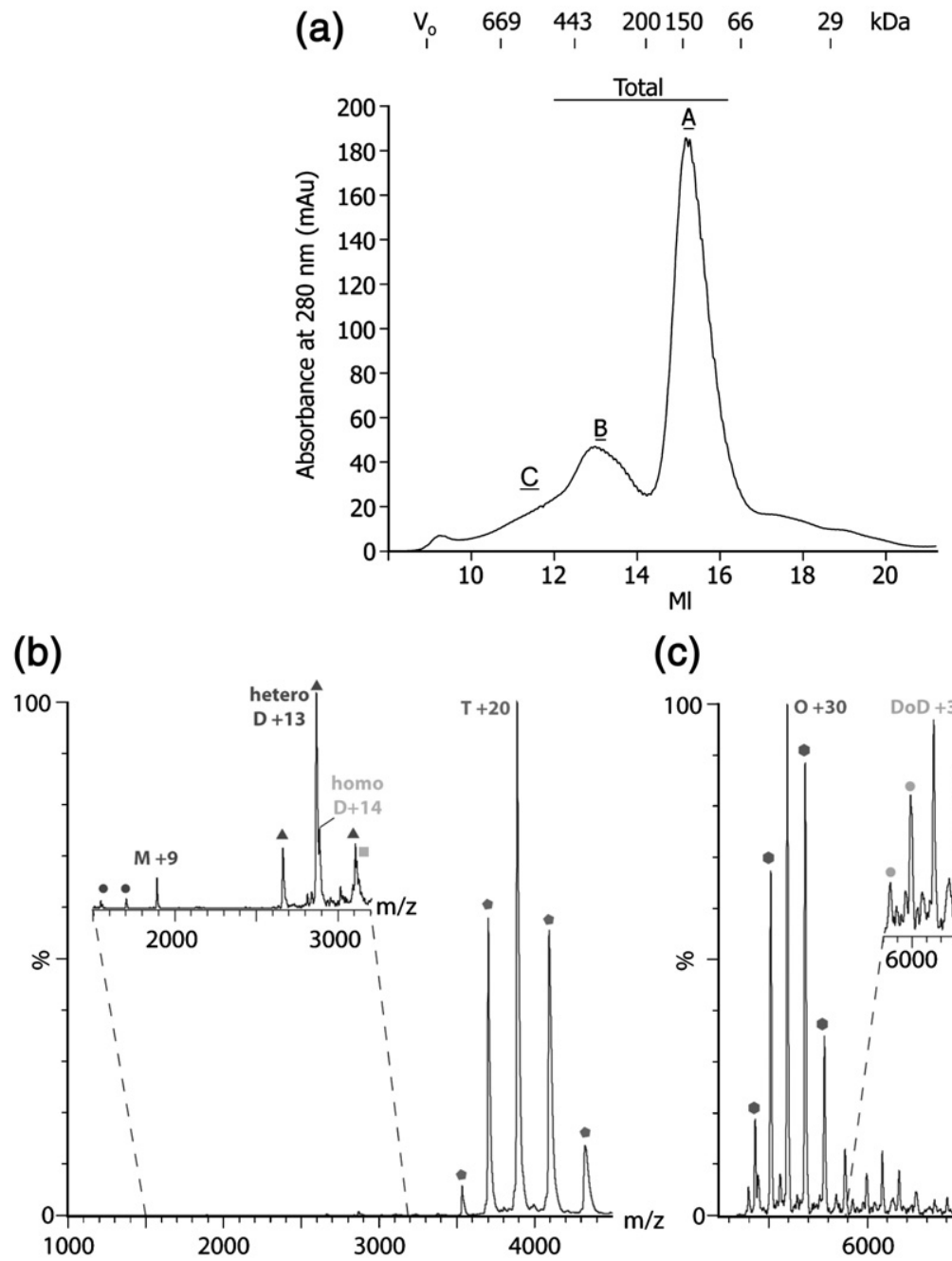

(c)

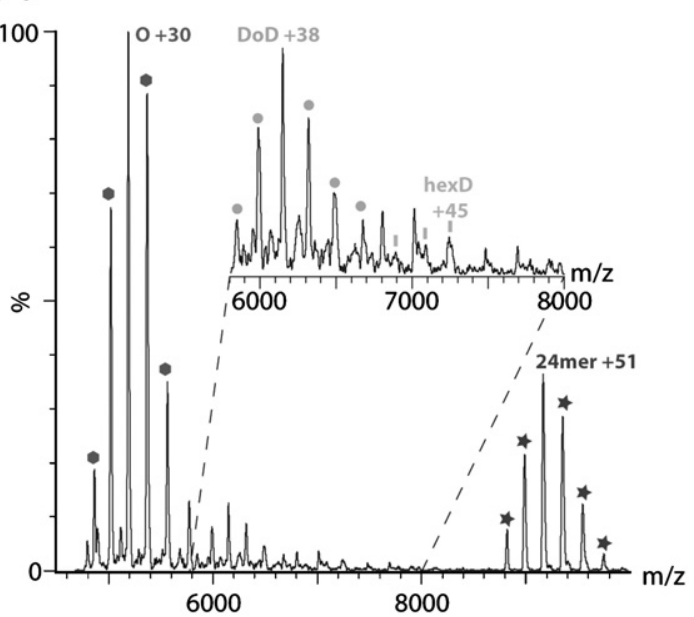

Fig. 2. Nanoelectrospray mass spectra of HSPB2/B3. a, HSPB2/B3 separated by passage through a Superose 6 column in $200 \mathrm{mM}$ ammonium acetate $\mathrm{pH}$ 6.8. Fractions of peaks A and B were collected. b, The higher oligomeric species observed by mass spectrometry acquired with a sample of peak A. The dominant charge state series correspond to a HSPB2/B3 tetramer (T) of mass $77897 \pm 34$ Da composed of three $20.2 \mathrm{kDa}$ subunits and a single $17.0 \mathrm{kDa}$ subunit. Inset in $\mathrm{b}$, an expansion of the $1500-3500 \mathrm{~m} / \mathrm{z}$ region. Here, three additional species can be identified: a monomer (M) with mass $17024 \pm 1 \mathrm{Da}$; a heterodimer (heteroD), with mass $37294 \pm 9 \mathrm{Da}$, composed of a single copy of each subunit and a homodimer (homoD), with mass $40458 \pm 39 \mathrm{Da}$, composed of two $20.2 \mathrm{kDa}$ subunits. c, The higher oligomeric species observed by mass spectrometry, acquired with a sample of peak B. The mass of the predominant charge state series in this spectrum corresponds to an octamer $(\mathrm{O})$ composed of six $20.2 \mathrm{kDa}$ subunits and two $17.0 \mathrm{kDa}$ in the same subunit ratio observed for the tetrameric species in $\mathrm{b}$. The next most intense peak series corresponds to that of a 24-mer with the 3:1 subunit ratio observed previously. The inset in c expands the $5700-8000 \mathrm{~m} / \mathrm{z}$ region of the spectrum. A well defined but low-intensity series for a dodecameric oligomer (DoD) with mass $233767 \pm 94$ Da was detected as well as a low-intensity series for a hexadecamer (hexD) with mass $311853 \pm 19 \mathrm{Da}$. Both the dodecamer and hexadecamer conform to the same subunit ratio observed for the tetramer, octamer and 24-mer. 


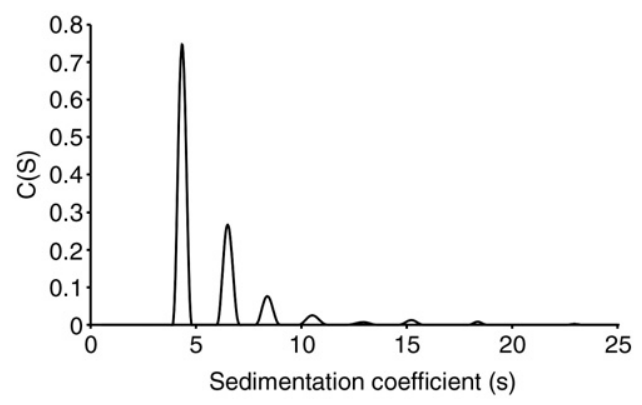

Fig. 3. Sedimentation velocity analysis of HSPB2/B3. Purified HSPB2/B3 at $0.5 \mathrm{mg} / \mathrm{mL}$ in $20 \mathrm{mM}$ phosphate buffer $\mathrm{pH} 7.5$ containing $100 \mathrm{mM} \mathrm{NaCl}$ and $2 \mathrm{mM}$ EDTA was centrifuged at $42,000 \mathrm{rpm}$ in An50-Ti rotor at $22^{\circ} \mathrm{C}$. A multi-species analysis of the results was used to calculate the $C(\mathrm{~s})$ distribution of $s_{\mathrm{w}}$.

MS) under conditions that preserve non-covalent interactions. ${ }^{31}$ The unprecedented accuracy of this technique can be used to calculate the exact subunit stoichiometry of the hetero-oligomers. Before mass spectrometry, the proteins were separated on a Superose 6 column, using a $200 \mathrm{mM}$ ammonium acetate buffer at $\mathrm{pH}$ 6.8, which gave a similar elution pattern with two relatively sharp peaks $A$ and $B$, and a broader peak C (Fig. 2a). This broadness is likely to be caused by the mass variations of the large complexes shown by the MALLS measurements (Fig. 1b). Mass spectra were collected for oligomeric HSPB2/B3 present in peak A and peak B containing a fraction of peak $C$. Analysis of peak A (Fig. $2 b$ ) revealed an intense series of peaks (T) with $m / z$ of 3500-5250, which emanated from an HSPB2/ B3 complex with a mass of $77,887 \pm 34$ Da. According to the mass, this is a tetrameric complex (T, 4-mer) composed of three HSPB2 subunits (calculated mass 20,235 Da) and one HSPB3 subunit (calculated mass 16,968 Da). A low-intensity charge state series with $\mathrm{m} / \mathrm{z}$ of $1500-3200$ could be observed (inset in $b$ ) in three different species: HSPB3 monomer with a mass of $17,024 \pm 1 \mathrm{Da}$, a heterodimer (heteroD) with a mass of $37,294 \pm 9 \mathrm{Da}$ (calculated mass 37,203 Da), and the HSPB2 homodimer (homoD) with a mass of $40,458 \pm 39 \mathrm{Da}$ (calculated mass 40,470 Da). The predominant charge state series found in peak B (Fig. 2c) corresponds with the mass of an octamer $(\mathrm{O}, 8$-mer) being 155,696 \pm 53 Da composed of six HSPB2 and two HSPB3 subunits. The next most intense peak series in this spectrum (mass $467,588 \pm 127 \mathrm{Da}$ ) corresponds to a 24-mer and has the same 3:1 subunit ratio observed for the tetra-and octameric complexes. A low-intensity charge state series with $\mathrm{m} / \mathrm{z}$ of 5800-8000 (inset in c) arose from a dodecamer (DoD, 12-mer) with a mass of 233,767 $\pm 94 \mathrm{Da}$ and another low-intensity series arose from a hexadecamer (hexD, 16 mer) with a mass of 311,853 \pm 19 Da. Both the dodecamer and hexadecamer conform to the same subunit ratio observed for the tetramer, octamer and 24-mer.

In order to determine the relative amount of each oligomeric complex, a sedimentation velocity centrifugation analysis, using an analytical ultracentrifuge (see Materials and Methods), was performed with $0.5 \mathrm{mg} / \mathrm{mL}$ of HSPB2/B3. By employing the $c(s)$ continuous distribution model, seven different complexes varying in sedimentation rate between $4.6 \mathrm{~S}$ and 19.4 S were identified (Fig. 3). On the basis of the calculated molecular masses of these complexes (Table 1), five of these complexes have been identified by nano-ESI-MS as being 4-, 8-, 12-, 16-and 24-mer. Another complex with the mass of a 20-mer was detected, which was not observed by nanoESI-MS, which is likely due to its low abundance. Beside these complexes, a large complex with a mass of 638,000 Da was detected by analytical ultracentrifugation, but the accuracy of this value was not sufficient to determine if this complex belongs to the series of well-defined oligomers. We determined the relative amount of each oligomer by measuring the peak areas, (Table 1). We found that the heterotetramer (4-mer) forms more than $60 \%$ of the amount of all species, which remained the same also at a 2fold higher concentration, indicating that this oligomer is the predominant form.

\section{Heat-induced structural changes of HSPB2/B3}

The chaperone-like activity of sHSPs is likely to be modulated by structural changes in response to stress, such as elevated temperatures. ${ }^{32}$ To assess heat-induced structural changes of HSPB2/B3, a

Table 1. Molecular masses of the detected HSPB2/B3 oligomers as determined by nano-ESI-MS, MALLS and sedimentation analysis and compared with the calculated masses

\begin{tabular}{|c|c|c|c|c|c|c|c|}
\hline \multicolumn{2}{|c|}{ Multimers } & \multirow{2}{*}{$\frac{\text { Nano-ESI-MS }}{\text { Mass (Da) }}$} & \multirow{2}{*}{$\begin{array}{c}\text { MALLS } \\
\text { Mass (Da) }\end{array}$} & \multicolumn{4}{|c|}{ Sedimentation velocity analysis (AUC) } \\
\hline$n$-mer & Calc. mass (Da) & & & $s_{20, w}(S)$ & Mass (Da) & Relative amount (\%) & $\begin{array}{c}\text { Ratio amount } \\
(n+4)-\text { mer } / n \text {-mer }\end{array}$ \\
\hline 4 & 77,673 & $77,897 \pm 34$ & 78,000 & 4.6 & 73,400 & 60.4 & - \\
\hline 8 & 155,346 & $155,696 \pm 53$ & 166,000 & 6.9 & 135,000 & 25.4 & 0,4 \\
\hline 12 & 233,019 & $233,767 \pm 94$ & - & 8.8 & 197,000 & 7.9 & 0,3 \\
\hline 16 & 310,692 & $311,853 \pm 19$ & - & 11.1 & 277,000 & 3.1 & 0,4 \\
\hline 20 & 388,365 & ND & - & 13.6 & 376,000 & 0.9 & 0,3 \\
\hline \multirow[t]{2}{*}{24} & 466,038 & $467,588 \pm 127$ & - & 16.0 & 481,000 & 1.3 & 1,4 \\
\hline & & & & 19.4 & 638,000 & 0.6 & - \\
\hline
\end{tabular}

ND, not detected. 
(a)

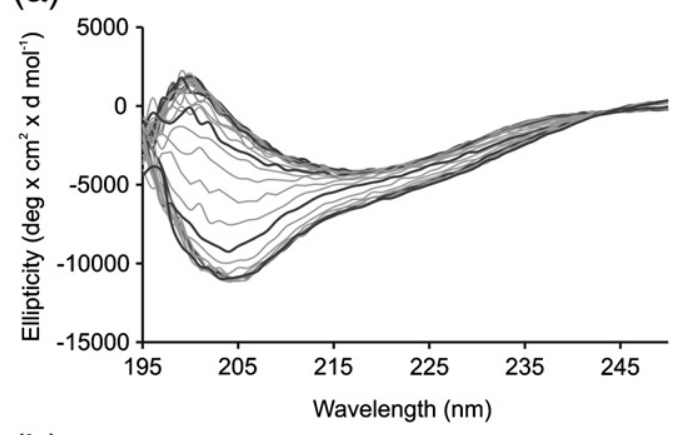

(b)

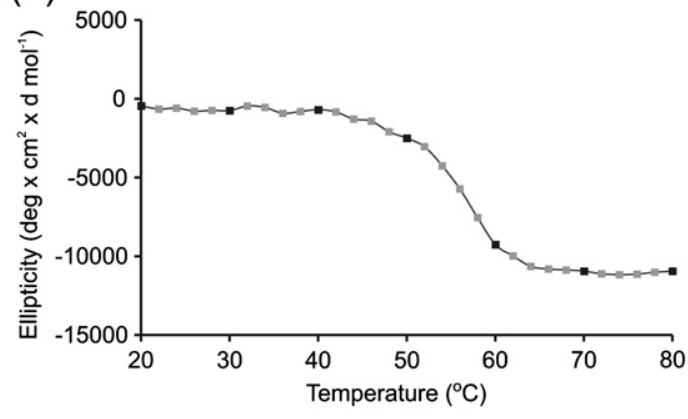

Fig. 4. Far-UV circular dichroism spectra of HSPB2/B3. a, Far-UV circular dichroism spectra; $b$, negative ellipticity at $204 \mathrm{~nm}$ of HSPB2/B3 taken after every increment of $2{ }^{\circ} \mathrm{C}$ from $20{ }^{\circ} \mathrm{C}$ to $80^{\circ} \mathrm{C}$. a, Dark lines indicate spectra; $\mathrm{b}$, dark squares indicate negative ellipticity at $204 \mathrm{~nm}$ taken after increments of $10^{\circ} \mathrm{C}$. Protein concentration was 250 $\mu \mathrm{g} / \mathrm{mL}$ in $10 \mathrm{mM}$ potassium phosphate buffer $\mathrm{pH} 7.8$.

series of far-UV circular dichroism (CD) spectra were recorded at temperatures in the range $20-$ $80{ }^{\circ} \mathrm{C}$, at which HSPB2/B3 remained soluble. The $\mathrm{CD}$ spectra for HSPB2/B3 collected between $20{ }^{\circ} \mathrm{C}$ and $40^{\circ} \mathrm{C}$ were quite similar and showed a relatively broad minimum around $215 \mathrm{~nm}$ (Fig. 4a). Above $40{ }^{\circ} \mathrm{C}$, a change in the spectra was observed, which was found to be most pronounced at $204 \mathrm{~nm}$. At this wavelength the negative ellipticity is characteristic for random coil structures caused by the unfolding of the subunits. ${ }^{33}$ By increasing the temperature, a two-step increase in this negative ellipticity at $204 \mathrm{~nm}$ could be recorded: first a slight elevation between $40{ }^{\circ} \mathrm{C}$ and $50{ }^{\circ} \mathrm{C}$ and secondly, a dramatic increase at temperatures between $50{ }^{\circ} \mathrm{C}$ and $64{ }^{\circ} \mathrm{C}$, with an inflection point of the unfolding curve at $56{ }^{\circ} \mathrm{C}$ (Fig. 4b).

\section{Surface hydrophobicity of HSPB2/B3}

The surface hydrophobicity of HSPB2/B3 was compared with that of $\alpha \mathrm{B}$-crystallin. $\alpha \mathrm{B}$-crystallin has a strong affinity for unfolding proteins, which correlates well to the surface hydrophobicity of this sHSP. ${ }^{34}$ The surface hydrophobicity was measured with the hydrophobic probe 1-anilino-8-naphthalenesulfonic acid ANS, a fluorescent dye with increasing fluorescence intensity upon binding to exposed hydrophobic surfaces. The fluorescence intensity was measured at different ANS/protein molar ratios (Fig. 5). Remarkably, even at high molar ratios very little fluorescent ANS signal was recorded for HSPB2/B3, indicating that HSPB2/B3 exhibits a very low ANS binding capacity compared to that of $\alpha \mathrm{B}$-crystallin. This indicates that the surface of HSPB2/B3 is relatively non-hydrophobic.

\section{HSPB2/B3 has poor chaperone-like and thermo- protective activity}

A low surface hydrophobicity is an indication for a poor chaperone-like activity. Three different chaperone assays were used to study the chaperone-like activity of HSPB2/B3 (Fig. 6). In the first assay, the ability to prevent aggregation of dithiothreitol (DTT)-denatured insulin was measured. In line with previous data, ${ }^{35}$ recombinant $\alpha \mathrm{B}$-crystallin fully inhibited the DTT-induced aggregation of insulin at a 1:1 mass ratio (Fig. 6a). Conversely, practically no prevention of insulin aggregation was observed in the presence of $0.25 \mathrm{mg} / \mathrm{mL} \mathrm{HSPB2/B3.}$ In the second assay, the ability to prevent the heatinduced aggregation of citrate synthase (CS) was assessed. ${ }^{36}$ At a 1:1 mass ratio, both $0.07 \mathrm{mg} / \mathrm{mL}$ HSPB2/B3 and $\alpha$ B-crystallin were able to prevent CS aggregation, although HSPB2/B3 showed significantly less chaperone-like activity than $\alpha \mathrm{B}-$ crystallin (Fig. 6b). In the third assay, the ability of HSPB2/B3 to confer thermotolerance to E. coli cells was established (Fig. 6c). E. coli cells expressing HSPB2/B3, $\alpha$ B-crystallin or the chaperone-like activity lacking negative control $\beta B 2$-crystallin, ${ }^{37}$ were heat-shocked for $60 \mathrm{~min}$ at $48{ }^{\circ} \mathrm{C}$, a temperature at which marginal unfolding of HSPB2/B3 was detected (Fig. 4b). After the heat-shock, cells were diluted in fresh medium and cell recovery at $37^{\circ} \mathrm{C}$ was monitored for $4.5 \mathrm{~h}$ by measuring the cell density $\left(A_{580}\right)$ at 30 min intervals. After $4.5 \mathrm{~h}$, a considerable growth recovery of $\alpha \mathrm{B}$-crystallin expressing cells was observed, while cells expressing HSPB2/B3 or the control protein were still not recovered. These results show that HSPB2/B3 has no (Fig. 6a and c) or only little (Fig. 6b) chaperone-

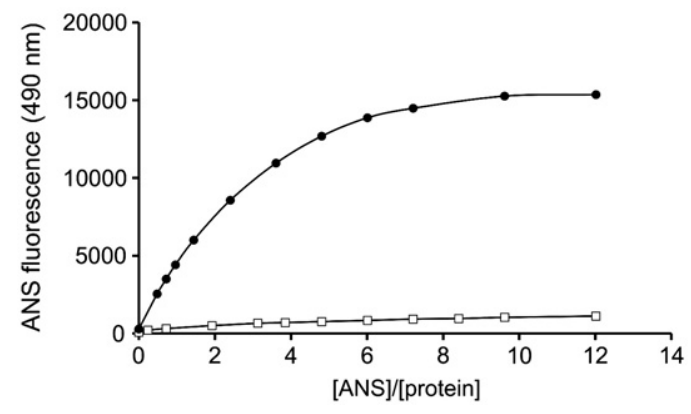

Fig. 5. HSPB2/B3 exhibits has a low affinity for the hydrophobic probe ANS. The ANS-binding capacity of HSPB2/B3 ( $\square$ ) and of $\alpha$ B-crystallin (๑) was determined by titrating $10 \mu \mathrm{M}$ protein with increasing concentrations of ANS (plotted as molar ratio ANS/protein) and measuring intensities of the fluorescence emission maxima with the excitation wavelength set at $390 \mathrm{~nm}$. 
(a)

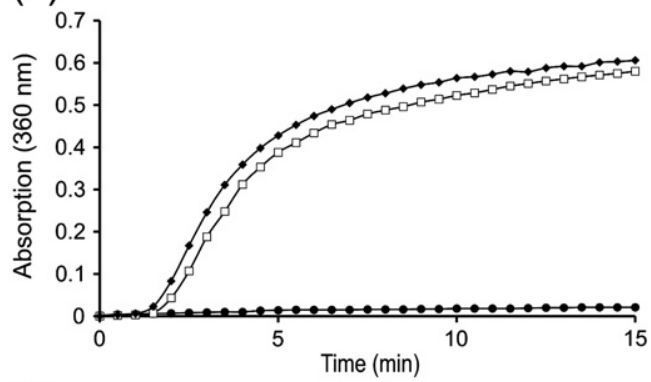

(b)

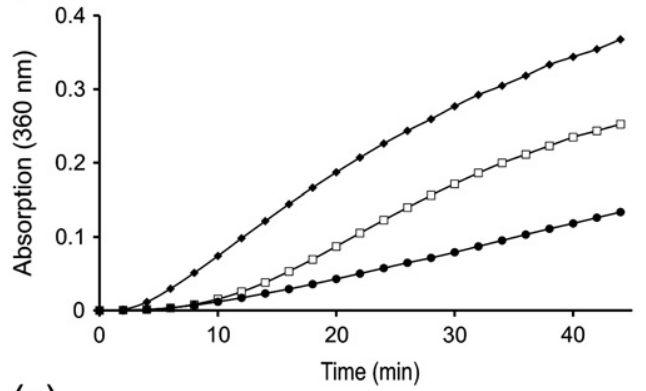

(c)

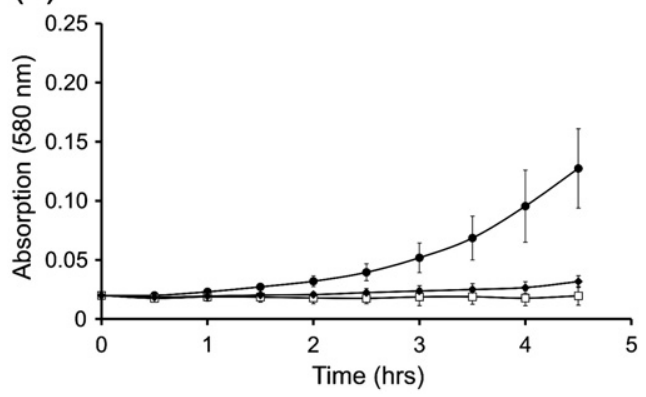

Fig. 6. HSPB2/B3 exhibits moderate chaperone-like and thermoprotective activity. (a) Chaperone activity of $250 \mu \mathrm{g}$ of HSPB2/B3 ( $\square$ ) or $\alpha$ B-crystallin (-) determined by measuring the ability to prevent DDT-induced aggregation of $250 \mu \mathrm{g}$ of insulin at $40^{\circ} \mathrm{C}$. Insulin alone is indicated by diamonds ( $\$$ ). (b) Chaperone activity of $70 \mu \mathrm{g}$ of HSPB2/B3 $(\square)$ or $\alpha$ B-crystallin $(\bullet)$ determined by measuring the ability to prevent temperature-induced aggregation of $70 \mu \mathrm{g}$ of CS at $44^{\circ} \mathrm{C}$. CS alone is indicated by diamonds ( ). (c) Thermoprotective activity of HSPB2/ $\mathrm{B} 3$ or $\alpha \mathrm{B}$-crystallin determined by measuring the growth

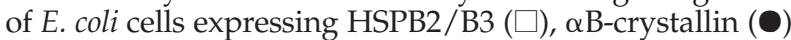
or negative control protein $\beta B 2(\diamond)$ after a heat-shock at $48^{\circ} \mathrm{C}$ for $60 \mathrm{~min}$.

like and thermoprotective activity in comparison to $\alpha \mathrm{B}$-crystallin.

\section{Interaction of HSPB2/B3 with other sHSPs}

HSPB2/B3 association in muscle cell extracts has been suggested to act mainly as an independent sHSP complex that does not associate with other sHSPs, such as HSP27 or $\alpha \mathrm{B}$-crystallin. However, a weak interaction between HSP20 and HSPB2 has been detected. ${ }^{21}$ To analyze whether the recombinant HSPB2/B3 oligomeric complexes exhibit similar associating properties, a mixture containing equal amounts of purified HSP20, HSP27 and $\alpha \mathrm{B}-$ crystallin was allowed to exchange subunits with HSPB2/B3. In this experiment, purified HSPB2 could be used as a control, because in a diluted form it remained soluble throughout the entire coimmunoprecipitation procedure. After incubation, HSPB2 was immunoprecipitated with HSPB2 antiserum followed by Western blot analysis to detect

(a)

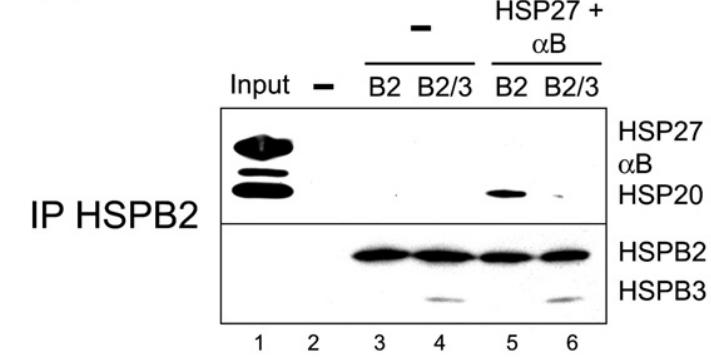

(b)

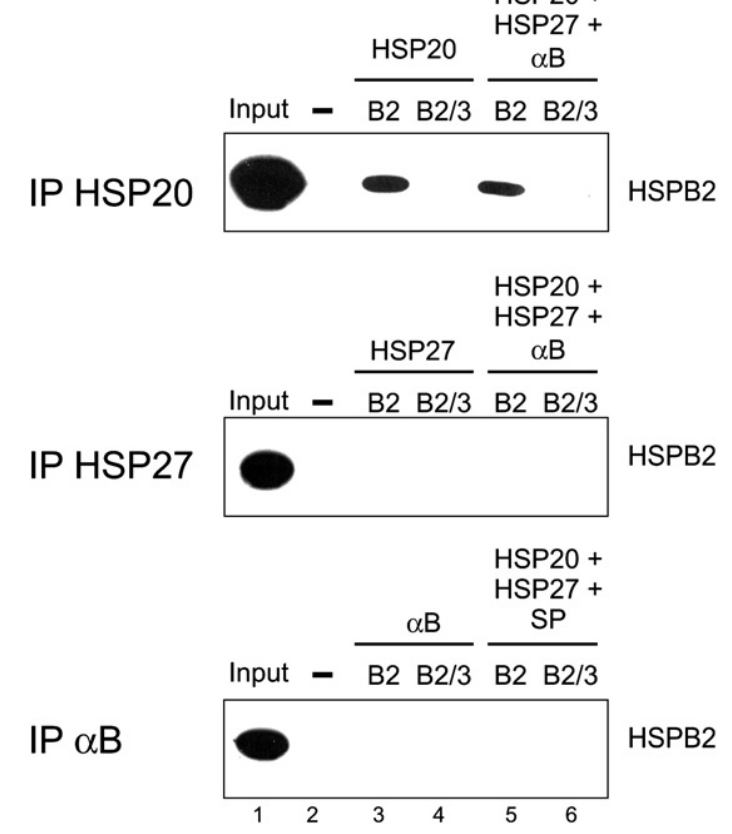

Fig. 7. HSPB2 but not HSPB2/B3 interacts with HSP20. a, Purified HSPB2 $(0.5 \mu \mathrm{g})$ and HSPB2/B3 $(1 \mu \mathrm{g})$ were incubated alone (lanes 3 and 4 ) or with a mixture of HSP20, HSP27 and $\alpha$ B-crystallin (each $5 \mu \mathrm{g}$ ) (lanes 5 and 6) for $60 \mathrm{~min}$ at room temperature and subsequently immunoprecipitated (IP) using antibodies directed to HSPB2. As a negative control, no protein was added (lane 2). The precipitated proteins were analyzed by Western blotting using antibodies directed to the indicated proteins. Lane 1 shows $5 \%$ of the input of HSP20, HSP27 and $\alpha$ B-crystallin. $b$, Purified HSPB2 $(0.5 \mu \mathrm{g})$ and HSPB2/B3 $(1 \mu \mathrm{g})$ were incubated with $5 \mu \mathrm{g}$ of HSP20 (upper panel), $5 \mu \mathrm{g}$ of HSP27 (middle panel) or $5 \mu \mathrm{g}$ of $\alpha$ B-crystallin (lower panel, lanes 3and 4) or with a mixture of the three proteins (each $5 \mu \mathrm{g}$ ) (lanes 5 and 6) for $60 \mathrm{~min}$ at room temperature and subsequently immunoprecipitated (IP) using the indicated antibodies. As a negative control, HSPB2/B3 was incubated with buffer alone (lane 2). The precipitated proteins were analyzed by Western blotting with anti-HSPB2 serum. Lane 1 shows $5 \%$ of the HSPB2/B3 input. 
the interacting proteins (Fig. 7a). As expected, HSPB3 was efficiently co-precipitated with HSPB2 (Fig. 7a, lanes 4 and 6). Surprisingly, HSP20 did not co-precipitate with HSPB2/B3, but was pulled down efficiently with HSPB2, while $\alpha \mathrm{B}$-crystallin and HSP27 co-precipitated neither with HSPB2/B3 nor HSPB2 (compare lanes 5 and 6).

In the reciprocal pull-down experiment, specific antibodies directed to HSP20, HSP27 and $\alpha \mathrm{B}-$ crystallin were used for the immunoprecipitation, and the co-precipitated HSPB2 was detected by Western blot analysis (Fig. 7b). All three sHSPs were incubated with HSPB2/B3 or HSPB2 either individually (Fig. 7b, lanes 3 and 4) or as a mixture (Fig. 7b, lanes 5 and 6). Again, only HSP20 showed a clear interaction with HSPB2, but not with HSPB2/B3. Curiously, no quantitative differences of co-precipitated HSPB2 were observed in the presence of HSP27 and $\alpha \mathrm{B}$-crystallin, indicating that the interaction between HSP20 and HSPB2 is not affected by these two sHSPs. These results show clearly that the HSPB2/B3 complex does not interact with HSP20, HSP27 or $\alpha$ B-crystallin, and HSPB2 can form a complex with HSP20 only in the absence of HSPB3.

\section{Discussion}

We succeeded in co-expressing HSPB2 and HSPB3 and purified the oligomeric complex of HSPB2/B3. HSPB3 was detected only as a component of this complex, while HSPB2 could be isolated as a separate homomeric assembly, albeit in a poorly soluble form. Analysis of the recombinant HSPB2/ B3 complex by the advanced methods of SECMALLS, nano-ESI-MS and sedimentation velocity centrifugation revealed the presence of a series of heteromeric oligomers. The masses of these oligomers varied from 77,897 - 467,588 Da, corresponding to assemblies containing from one to six tetramers, each comprising three HSPB2 and one HSPB3 subunits (Table 1). The tetramer is the most abundant oligomeric species that can be formed by HSPB2 and HSPB3. On the basis of the mass differences between the higher oligomers, we suggest this structure as the building block of the large HSPB2/B3 complexes. In addition, the 24-mer is likely to be a stable structure, because the existence of this complex is relatively more pronounced as determined by both nano-ESI-MS (Fig. 2c) and sedimentation analysis (compare the ratio of the amounts of $(n+4)$-and $n$-mer in Table 1$)$. The organization of HSPB2/B3 in distinct oligomeric structures is a very conspicuous feature, which to our knowledge, is a feature that has not been observed for other sHSPs.

On the basis of our SEC analysis, the main HSPB2/B3 complex was estimated to be in the range of an octamer, $150 \mathrm{kDa}$ (Fig. 2a, peak A), which is in good agreement with earlier reports. ${ }^{21,23,39}$ However, this is twice as large as was found by mass spectrometry, MALLS and sedimentation velocity centrifugation analysis (Figs. 1 and 2b). Since the accuracy of these latter techniques is much higher, it is likely that HSPB2/B3 elutes faster from a sizeexclusion column than would be expected on the basis of its mass. This aberrant behavior could be due to an atypical shape, such as the presence of extra space inside the complex. ${ }^{40}$

We found by heat-induced denaturation that HSPB2/B3 forms a relatively stable structure, which forms extensive random coil structures only at a temperature of $\sim 56^{\circ} \mathrm{C}$. However, the unfolding starts at $40{ }^{\circ} \mathrm{C}$, which suggests that structural changes already occur at this temperature. Such structural changes at close to physiological temperatures have been described for other sHSPs, and might be an important mechanism to regulate their chaperone-like activity. ${ }^{32}$

It was shown earlier that the $\alpha$-crystallin domain is needed to form the dimer structures, while the $\mathrm{N}$-terminal and C-terminal tails are involved mainly in stabilizing the quaternary structure. ${ }^{38}$ The Cterminal extensions can form critical bridges between neighboring subunits via a conserved IXI/V sequence. ${ }^{12}$ The C-terminal extension of HSPB2 does not contain this conserved sequence but, on the basis of its length, it could still be involved in stabilizing the quaternary structure. However, HSPB3 has an extension of about five residues, which is likely to be too short to form a bridge between adjacent $\alpha$-crystallin domain dimers (Fig. 8). The absence of a a long C-terminal extension in HSPB3 might be an important factor for the unique nature of the HSPB2/ B3 complex to form tetramers that can subsequently assemble into multiple oligomers.

sHSPs expressed in the same cell often form heteromeric complexes consisting of several sHSPs, such as those described for $\alpha B$-crystallin and HSP27. ${ }^{41}$ There are also examples in which more than one type of sHSP oligomeric complexes can exist in the cytoplasm of a single cell. In higher plants, class I and II sHSPs are proteins that can be found in separate oligomers. ${ }^{42}$ Likewise, HSPB2 and HSPB3 form separate oligomers distinct from the HSP27HSP20- $\alpha$ B-crystallin assembly, despite their co-expression with e.g. HSP27, HSP20 and $\alpha \mathrm{B}$-crystallin in muscle cells. Interestingly, HSP20 is able to interact with HSPB2, ${ }^{21}$ which raised the question of whether HSP20 can interact also with HSPB2 as part of the HSPB2/B3 complex. We have shown by co-immunoprecipitation experiments that the HSPB2/B3

\section{human HSPB2 GRHLDTEVNEVYISLLPAPPDPEEEEEAAIVEP rat HSPB2 GRHLDTEVNEVYISLLPAPPDPEEEEEVARVEP \\ human HSPB3 PVGTK \\ rat HSPB3 PLETK}

Fig. 8. Protein sequence alignment of the C-terminal extension of human and rat HSPB2 and HSPB3. The Cterminal extensions of HSPB2 and HSPB3 consist of 33 and 5 amino acid residues, respectively, of which the conserved residues are highlighted in gray boxes. Accession numbers were: human HSPB2 (Q160082), rat HSPB2 (O35878), human HSPB3 (Q12988) and rat HSPB3 (Q9QZ58). 
complex does not interact with HSP20 (Fig. 7). Only HSPB2 alone, thus not in complex with HSPB3, binds to HSP20 relatively well. Interestingly, this interaction was not influenced by $\alpha \mathrm{B}$-crystallin or HSP27, which are both known interacting partners of Hsp20. These data show that HSPB2/B3 is indeed a separate complex not able to interact with other sHSPs. Moreover, it is also in good agreement with the yeast two-hybrid studies showing that only HSP20 and HSPB3 are able to interact with HSPB2, ${ }^{21}$ while HSPB3 interacts only with HSPB2 and not with other sHSPs. ${ }^{43}$ Recently, HSPB8 (HSP22) has been found to interact also with HSPB2 and not with HSPB3 and may have a binding specificity similar to that of HSP20. ${ }^{39}$ The concentration of HSPB2 and HSPB3 in rat skeletal muscle extract was found to be 0.30 and $0.09 \mu \mathrm{g} / \mathrm{mg}$ of total protein, respectively. ${ }^{21}$ Thus, the ratio of expression between the two proteins is close to 3:1, which suggests that virtually all HSPB2 is part of the HSPB2/B3 complex. This may explain why only a minor fraction of HSPB2 associates with HSP20 in muscle tissue extract. ${ }^{21}$

HSPB2/B3 hardly binds ANS (Fig. 5), indicating that the surface of the complex is not very hydrophobic. We cannot exclude the possibility that hydrophobic interfaces are buried inside the complex, which, due to a low dynamic exchange of subunits between the oligomers are not exposed. The low surface hydrophobicity is likely to affect the binding of unfolding proteins, ${ }^{44}$ and in this way it contributes to the observed poor chaperone-like activity of the HSPB2/B3 complex. Interestingly, purified homomeric HSPB2 has been shown to have chaperone-like activity that protects the kinase DMPK from heat-induced inactivation. ${ }^{23}$ By using a diluted preparation of purified HSPB2, we could detected a moderate chaperone-like activity of HSPB2 for insulin (data not shown). It is thus possible that HSPB3, at least in part, is responsible for the low chaperone-like activity of the HSPB2/B3 complex and has to dissociate from the complex to render HSPB2 its chaperone-like activity. However, the relation between in vitro and in vivo chaperone-like activity does not always correspond to each other ${ }^{45}$. It is possible that HSPB2/B3 function as a chaperone complex in vivo, possibly only dedicated to specific substrates.

In summary, this study shows that HSPB2/B3 forms a series of heterooligomers with a welldefined subunit ratio and differ in number of tetramers. They have poor chaperoning activity and do not interact with other sHSPs, which is atypical compared to other sHSPs. Further studies are needed to understand the structural and cellular functions of this complex.

\section{Materials and Methods}

\section{Cloning, expression and purification}

The cDNAs encoding rat HSPB2 and rat HSPB3 were cloned into the pET3a expression vector by using the
NdeI-BamHI sites and BglII-EcoRI sites, respectively. Protein expression was induced in the BL21 Rosetta strain, transformed with pET3a-HSPB2/B3, by addition of IPTG to a final concentration of $350 \mu \mathrm{M}$ and subsequent incubation for $3 \mathrm{~h}$ at $37^{\circ} \mathrm{C}$. Cells were lysed by sonication in TEG buffer (25 mM Tris, pH 8.0, 2 mM EDTA, $50 \mathrm{mM}$ glucose) and then centrifuged at $16,000 \mathrm{~g}$ for $45 \mathrm{~min}$ at $4^{\circ} \mathrm{C}$. The obtained supernatants were subjected to precipitation in $0.12 \%(\mathrm{w} / \mathrm{v})$ polyethyleneimine. SHSPs were first fractionated on a DEAE-Sepharose column, using a gradient of $0-1 \mathrm{M} \mathrm{NaCl}$ in $25 \mathrm{mM}$ bis-Tris $\mathrm{pH}$ 6.35, 2 mM EDTA and, after desalting, further fractionated on a Source 15Q HR 16/10 column using the same salt gradient. This yielded fractions containing both HSPB2 and HSPB3, and HSPB2 alone. Recombinant HSP27, HSP20 and $\alpha$ B-crystallin were purified in a similar manner, using pET3a-human-HSP27, pET8c-rat-HSP20 and pET3b-human- $\alpha$ B-crystallin as described. ${ }^{46}$

\section{SEC-MALLS}

SEC-MALLS analysis was done by chromatographic separation of samples $(100 \mu \mathrm{g})$, on an Agilent 1200 system, using a TSK-Gel3000SW column (TOSOH-BIOSEP) at a flow rate of $0.5 \mathrm{~mL} / \mathrm{min}$ in $10 \mathrm{mM}$ sodium citrate, $\mathrm{pH}$ $6.25,100 \mathrm{mM} \mathrm{NaCl}$. MALLS analysis of a sample was done continuously on the column eluate, as it passed through a triple-angle miniDAWNTM TREOS lightscattering detector in series with an Optilab rEX refractive index instrument (both from Wyatt Technologies, Inc). Data were analyzed using Astra v5.3.2, a $\mathrm{d} n / \mathrm{d} c$ value of 0.185 , an $A_{2}$ value of 0 , and a first order Zimm fit.

\section{Far-UV circular dichroism (CD) spectroscopy}

CD spectra were recorded on a J-810 spectropolarimeter (Jasco) in a $1 \mathrm{~mm}$ pathlength cuvette using $250 \mu \mathrm{g} / \mathrm{mL}$ of HSPB2/B3 dialyzed against $10 \mathrm{mM}$ potassium phosphate buffer $\mathrm{pH}$ 7.8. Spectra of HSPB2/B3 and buffer alone were recorded between $195 \mathrm{~nm}$ and $250 \mathrm{~nm}$ with a scanning speed of $20 \mathrm{~nm} / \mathrm{min}$ with a response time of $1 \mathrm{~s}$ and a bandwidth set to $1 \mathrm{~nm}$. To determine the heat stability, the temperature of the cuvette was increased from $20{ }^{\circ} \mathrm{C}$ to $80^{\circ} \mathrm{C}$ at a heating rate of $1^{\circ} \mathrm{C} / \mathrm{min}$. After each increment of $2{ }^{\circ} \mathrm{C}, 15$ spectra were recorded and averaged. The spectra of HSPB2/B3 were corrected for the spectra of the buffer at the corresponding temperatures.

\section{Mass spectrometry}

HSPB2/B3 was buffer exchanged from the initial buffer into200 mM ammonium acetate, $\mathrm{pH} 6.8$, using a Superdex 200 column on an AKTA prime FPLC and subsequently separated into two fractions, A and B, on a Superose 6 column. From these fractions, nanoelectrospray mass spectra were acquired using a Qstar XL mass spectrometer (MDS Sciex), under conditions optimized for the transmission of non-covalent protein complex interactions, using a published protocol. ${ }^{47}$ Typical instrument parameters in positive ion mode, were: ion spray voltage $1.2 \mathrm{kV}$, declustering potential $100-150 \mathrm{~V}$, focusing potential $100 \mathrm{~V}$, declustering potential $215 \mathrm{~V}$, quadrupole voltage (Q0) $50 \mathrm{~V}$, collision gas (CAD) 6, ion release delay 6 and ion release width 5 . Experiments were acquired at an instrument base pressure of 6.5 mbar. 


\section{Analytical ultracentrifugation}

Samples were placed in assembled cells with sapphire windows and $12 \mathrm{~mm}$ pathlength centerpieces, which were made of charcoal-filled epon, and were centrifuged at 42,000 rpm in an 8-hole An50-Ti rotor. The data were collected using the absorption detection system of the XL-I analytical ultracentrifuge (Beckman Coulter) at $276 \mathrm{~nm}$. The cells were aligned manually, the inner cell housing scribe line on the bottom of the cell was aligned visually with the inner rotor hole scribe lines. Once the vacuum was less than 5 micron, the rotor was allowed to reach the set temperature of $22{ }^{\circ} \mathrm{C}$ and then was equilibrated for $1 \mathrm{~h}$ before accelerating the rotor to the maximum speed of $42,000 \mathrm{rpm}$. The cells were scanned at $276 \mathrm{~nm}$ as frequently as possible, using a radial increment of $0.003 \mathrm{~cm}$. At the end of the experiment, the data were analyzed by Sedfit. ${ }^{48}$

The $c(s)$ continuous distribution model was used with input parameters that include radial position for the cell bottom and initial position for the meniscus, an initial estimate of frictional coefficient ratio $\left(f / f_{0}\right)$ of 1.2 , the radial data range and sedimentation coefficient range (0.5-20 S, the resolution was set at 200) for fitting. The solvent density and viscosity as well as the partial specific volume were calculated using the public domain software program Sednterp. ${ }^{49}$ The calculated partial specific volume of the HSPB2/B3 oligomer was corrected for the subunit ratio of 3:1. An initial $c(s)$ distribution was generated using these parameters. Subsequently, it was optimized using the meniscus position and $f / f_{0}$ as floating parameters. Using the integration tool provided in Sedfit, the relative concentration and weight average sedimentation coefficients were determined for each species. In all cases, regularization with Tikhonov-Phillips obtained the best results. The root-mean-square deviation (rmsd) for all analysis was $<0.004$.

\section{ANS binding}

To study the binding of the hydrophobic probe ANS, 10 $\mu \mathrm{M}$ HSPB2/B3 in $10 \mathrm{mM}$ sodium phosphate buffer $(\mathrm{pH}$ 7.4) containing $100 \mathrm{mM} \mathrm{NaCl}$ and $500 \mathrm{mM}$ ANS in methanolic solution was used to make a series of mixtures with different molar ratios. The mixtures were incubated for $10 \mathrm{~min}$ at $37^{\circ} \mathrm{C}$, after which the fluorescence emission was measured at $490 \mathrm{~nm}$ using an excitation wavelength of $390 \mathrm{~nm}$.

\section{Chaperone assays}

To measure the chaperone-like properties of sHSPs, the insulin protection assay described by Farahbakhsh et al. ${ }^{35}$ and the CS assay described by Kappé et al. ${ }^{36}$ were used. Briefly, for the insulin protection assay, the proteins were dialyzed overnight at $4{ }^{\circ} \mathrm{C}$ against buffer containing $20 \mathrm{mM}$ sodium phosphate, $\mathrm{pH} 6.9$, and $20 \mathrm{mM} \mathrm{Na}_{2} \mathrm{SO}_{4}$. In a final volume of $1 \mathrm{~mL}, 250 \mu \mathrm{g}$ of HSPB2/B3 or $\alpha \mathrm{B}-$ crystallin was incubated with $250 \mu \mathrm{g}$ of bovine insulin (Sigma) at $40^{\circ} \mathrm{C}$ for $5 \mathrm{~min}$. The denaturation of insulin was initiated by adding $3 \mathrm{mg}$ of DTT, and absorbance was measured at $360 \mathrm{~nm}\left(A_{360}\right)$ for $15 \mathrm{~min}$ at $40^{\circ} \mathrm{C}$ in a Perkin Elmer Lambda 2 UV/VIS spectrophotometer. For the CS protection assay, the proteins were dialyzed overnight at $4{ }^{\circ} \mathrm{C}$ against $40 \mathrm{mM}$ Hepes- $\mathrm{KOH}, \mathrm{pH}$ 7.5. A sample $(70 \mu \mathrm{g})$ of sHSP was incubated at $44{ }^{\circ} \mathrm{C}$ for $5 \mathrm{~min}$. After adding $70 \mathrm{mg}$ of CS to a total volume of $1 \mathrm{~mL}$ the heat-induced denaturation of the substrate at $44{ }^{\circ} \mathrm{C}$ was followed by measuring the turbidity at $360 \mathrm{~nm}$ for $45 \mathrm{~min}$ in a Perkin Elmer Lambda 2 UV/VIS spectrophotometer.

\section{Colony survival assay}

Cells transformed with the appropriate bacterial expression construct were grown overnight. All cell suspensions were then diluted to $A_{580}=0.6$, and protein expression was induced for $1 \mathrm{~h}$ by adding $350 \mu \mathrm{M}$ IPTG. After induction, cells were heat-shocked at $48{ }^{\circ} \mathrm{C}$ for $60 \mathrm{~min}$, after which the cell cultures were diluted to $A_{580}=0.06$. The recovery was monitored for $4.5 \mathrm{~h}$ at $37^{\circ} \mathrm{C}$ by measuring the increase of $A_{580}$ at 30 min intervals.

\section{Co-immunoprecipitation assay}

Purified HSPB2/B3 $(1 \mu \mathrm{g})$ and HSPB2 $(0.5 \mu \mathrm{g})$ were incubated either alone (negative control) or together with HSP20, HSP27, $\alpha$ B-crystallin $(5 \mu \mathrm{g})$ or a mixture of the three proteins (each $5 \mu \mathrm{g})$ in TEN buffer $(25 \mathrm{mM}$ Tris $\mathrm{pH}$ 8.0, $100 \mathrm{mM} \mathrm{NaCl}, 2 \mathrm{mM}$ EDTA and $0.05 \%(\mathrm{v} / \mathrm{v}) \mathrm{NP} 40)$ for $60 \mathrm{~min}$ at room temperature. After the incubation, antibodies directed against HSPB2, HSP20, $\alpha$ B-crystallin (all three raised in rabbits) or HSP27 (Stressgen) coupled to protein A beads (Roche) were added to the indicated mixtures and mixed by rotation for $60 \mathrm{~min}$. The beads were then pelleted and washed three times with $1 \mathrm{~mL}$ of TEN buffer. The proteins bound to the beads were separated by SDS-PAGE and analyzed by Western blotting.

\section{Acknowledgements}

We thank Dr Guido Kappé for helpful discussions and technical assistance, and Carolien Vercouteren and Jurgen Ketelaars for their technical assistance. This work was supported by grant NWO-MW 90351-170 from the Netherlands Organization for Scientific Research (to W.C.B.) and by the Hungarian Eötvös Fellowship (to C.S.B.)

\section{References}

1. Haslbeck, M., Franzmann, T., Weinfurtner, D. \& Buchner, J. (2005). Some like it hot: the structure and function of small heat-shock proteins. Nat. Struct. Mol. Biol. 12, 842-846.

2. Sun, Y. \& Macrae, T. H. (2005). Small heat-shock proteins: molecular structure and chaperone function. Cell Mol. Life Sci. 62, 2460-2476.

3. Taylor, R. P. \& Benjamin, I. J. (2005). Small heat-shock proteins: a new classification scheme in mammals. $J$. Mol. Cell Cardiol. 38, 433-444.

4. Kim, K. K., Kim, R. \& Kim, S. H. (1998). Crystal structure of a small heat-shock protein. Nature, 394, 595-599.

5. Stamler, R., Kappe, G., Boelens, W. \& Slingsby, C. (2005). Wrapping the alpha-crystallin domain fold in a chaperone assembly. J. Mol. Biol. 353, 68-79.

6. Van Montfort, R. L., Basha, E., Friedrich, K. L., Slingsby, C. \& Vierling, E. (2001). Crystal structure and assembly of a eukaryotic small heat-shock protein. Nat. Struct. Biol. 8, 1025-1030. 
7. Pasta, S. Y., Raman, B., Ramakrishna, T. \& Rao, C (2003). Role of the conserved SRLFDQFFG region of alpha-crystallin, a small heat-shock protein. Effect on oligomeric size, subunit exchange, and chaperone-like activity. J. Biol. Chem. 278, 51159-51166.

8. Stromer, T., Fischer, E., Richter, K., Haslbeck, M. \& Buchner, J. (2004). Analysis of the regulation of the molecular chaperone Hsp26 by temperature-induced dissociation: the $\mathrm{N}$-terminal domail is important for oligomer assembly and the binding of unfolding proteins. J. Biol. Chem. 279, 11222-11228.

9. Theriault, J. R., Lambert, H., Chavez-Zobel, A. T. Charest, G., Lavigne, P. \& Landry, J. (2004). Essential role of the NH2-terminal WD/EPF motif in the phosphorylation-activated protective function of mammalian Hsp27. J. Biol. Chem. 279, 23463-23471.

10. Carver, J. A. (1999). Probing the structure and interactions of crystallin proteins by NMR spectroscopy. Prog. Retin. Eye Res. 18, 431-462.

11. Li, Y., Schmitz, K. R., Salerno, J. C. \& Koretz, J. F (2007). The role of the conserved $\mathrm{COOH}$-terminal triad in alphaA-crystallin aggregation and functionality. Mol. Vis. 13, 1758-1768.

12. Saji, H., Iizuka, R., Yoshida, T., Abe, T., Kidokoro, S. Ishii, N. \& Yohda, M. (2008). Role of the IXI/V motif in oligomer assembly and function of StHsp14.0, a small heat-shock protein from the acidothermophilic archaeon, Sulfolobus tokodaii strain 7. Proteins: Struct. Funct. Genet. 71, 771-782.

13. Horwitz, J. (1992). Alpha-crystallin can function as a molecular chaperone. Proc. Natl Acad. Sci. USA, 89, 10449-10453.

14. Jakob, U., Gaestel, M., Engel, K. \& Buchner, J. (1993). Small heat-shock proteins are molecular chaperones. J. Biol. Chem. 268, 1517-1520.

15. Arrigo, A. P., Simon, S., Gibert, B., Kretz-Remy, C., Nivon, M. \& Czekalla, A Vicart, P. (2007). Hsp27 (HspB1) and alphaB-crystallin (HspB5) as therapeutic targets. FEBS Lett. 581, 3665-3674.

16. Fan, G. C., Chu, G. \& Kranias, E. G. (2005). Hsp20 and its cardioprotection. Trends Cardiovasc. Med. 15, 138-141.

17. Shemetov, A. A., Seit-Nebi, A. S. \& Gusev, N. B. (2008). Structure, properties, and functions of the human small heat-shock protein HSP22 (HspB8, H11, E2IG1): a critical review. J. Neurosci. Res. 86, 264-269.

18. Fontaine, J. M., Rest, J. S., Welsh, M. J. \& Benndorf, R. (2003). The sperm outer dense fiber protein is the 10th member of the superfamily of mammalian small stress proteins. Cell Stress. Chaperones, 8, 62-69.

19. Kappe, G., Franck, E., Verschuure, P., Boelens, W. C., Leunissen, J. A. \& de Jong, W. W. (2003). The human genome encodes 10 alpha-crystallin-related small heat-shock proteins: HspB1-10. Cell Stress. Chaperones, 8, 53-61.

20. Hu, Z., Yang, B., Lu, W., Zhou, W., Zeng, L., Li, T. \& Wang, X. (2008). HSPB2/MKBP, a novel and unique member of the small heat-shock protein family. J. Neurosci. Res. 86, 2125-2133.

21. Sugiyama, Y., Suzuki, A., Kishikawa, M., Akutsu, R., Hirose, T. \& Waye, M. M Ohno, S. (2000). Muscle develops a specific form of small heat-shock protein complex composed of MKBP/HSPB2 and HSPB3 during myogenic differentiation. J. Biol. Chem. 275, 1095-1104.

22. Verschuure, P., Tatard, C., Boelens, W. C., Grongnet, J. F. \& David, J. C. (2003). Expression of small heatshock proteins HspB2, HspB8, Hsp20 and cvHsp in different tissues of the perinatal developing pig. Eur. J. Cell Biol. 82, 523-530.

23. Suzuki, A., Sugiyama, Y., Hayashi, Y., Nyu-i, N, Yoshida, M. \& Nonaka, I Ohno, S. (1998). MKBP, a novel member of the small heat-shock protein family, binds and activates the myotonic dystrophy protein kinase. J. Cell Biol, 140, 1113-1124.

24. Kadono, T., Zhang, X. Q., Srinivasan, S., Ishida, H., Barry, W. H. \& Benjamin, I. J. (2006). CRYAB and HSPB2 deficiency increases myocyte mitochondrial permeability transition and mitochondrial calcium uptake. J. Mol. Cell Cardiol. 40, 783-789.

25. Nakagawa, M., Tsujimoto, N., Nakagawa, H., Iwaki, T., Fukumaki, Y. \& Iwaki, A. (2001). Association of HSPB2, a member of the small heat-shock protein family, with mitochondria. Exp. Cell Res. 271, 161-168.

26. Pinz, I., Robbins, J., Rajasekaran, N. S., Benjamin, I. J. \& Ingwall, J. S. (2008). Unmasking different mechanical and energetic roles for the small heat-shock proteins $\mathrm{CryAB}$ and HSPB2 using genetically modified mouse hearts. FASEB J. 22, 84-92.

27. Wilhelmus, M. M., Otte-Holler, I., Wesseling, P., de Waal, R. M., Boelens, W. C. \& Verbeek, M. M. (2006). Specific association of small heat-shock proteins with the pathological hallmarks of Alzheimer's disease brains. Neuropathol. Appl. Neurobiol. 32, 119-130.

28. Wilhelmus, M. M., Boelens, W. C., Otte-Holler, I., Kamps, B., de Waal, R. M. \& Verbeek, M. M. (2006). Small heat-shock proteins inhibit amyloid-beta protein aggregation and cerebrovascular amyloid-beta protein toxicity. Brain Res. 1089, 67-78.

29. Boelens, W. C., van Boekel, M. A. \& de Jong, W. W. (1998). HspB3, the most deviating of the six known human small heat-shock proteins. Biochim. Biophys. Acta, 1388, 513-516.

30. Verschuure, P., Croes, Y., van den IJssel, P. R., Quinlan, R. A., de Jong, W. W. \& Boelens, W. C. (2002). Translocation of small heat-shock proteins to the actin cytoskeleton upon proteasomal inhibition. J. Mol. Cell Cardiol. 34, 117-128.

31. Sobott, F., McCammon, M. G., Hernandez, H. \& Robinson, C. V. (2005). The flight of macromolecular complexes in a mass spectrometer. Phil. Trans. A, 363, 379-389.

32. Reddy, G. B., Das, K. P., Petrash, J. M. \& Surewicz, W. K. (2000). Temperature-dependent chaperone activity and structural properties of human alphaAand alphaB-crystallins. J. Biol. Chem. 275, 4565-4570.

33. Receveur-Brechot, V., Bourhis, J. M., Uversky, V. N., Canard, B. \& Longhi, S. (2006). Assessing protein disorder and induced folding. Proteins: Struct. Funct. Genet. 62, 24-45.

34. Benesch, J. L., Ayoub, M., Robinson, C. V. \& Aquilina, J. A. (2008). Small heat-shock protein activity is regulated by variable oligomeric substructure. J. Biol. Chem. 283, 28513-28517.

35. Farahbakhsh, Z. T., Huang, Q. L., Ding, L. L., Altenbach, C., Steinhoff, H. J., Horwitz, J. \& Hubbell, W. L. (1995). Interaction of alpha-crystallin with spinlabeled peptides. Biochemistry, 34, 509-516.

36. Kappe, G., Aquilina, J. A., Wunderink, L., Kamps, B., Robinson, C. V. \& Garate, T de Jong, W. W. (2004). Tsp36, a tapeworm small heat-shock protein with a duplicated alpha-crystallin domain, forms dimers and tetramers with good chaperone-like activity. Proteins: Struct. Funct. Genet. 57, 109-117.

37. Evans, P., Slingsby, C. \& Wallace, B. A. (2008). Association of partially folded lens betaB2-crystallins 
with the alpha-crystallin molecular chaperone. Biochem. J. 409, 691-699.

38. van Montfort, R., Slingsby, C. \& Vierling, E. (2001) Structure and function of the small heat-shock protein/alpha-crystallin family of molecular chaperones. Adv. Protein Chem. 59, 105-156.

39. Sun, X., Fontaine, J. M., Rest, J. S., Shelden, E. A. Welsh, M. J. \& Benndorf, R. (2004). Interaction of human HSP22 (HSPB8) with other small heat-shock proteins. J. Biol. Chem. 279, 2394-2402.

40. White, H. E., Orlova, E. V., Chen, S., Wang, L. Ignatiou, A., Gowen, B. et al. (2006). Multiple distinct assemblies reveal conformational flexibility in the small heat-shock protein Hsp26. Structure, 14, 1197-1204.

41. Zantema, A., Verlaan-De Vries, M., Maasdam, D., Bol, S. \& van der, E. A. (1992). Heat-shock protein 27 and alpha B-crystallin can form a complex, which dissociates by heat-shock. J. Biol. Chem. 267, 12936-12941.

42. Helm, K. W., Lee, G. J. \& Vierling, E. (1997). Expression and native structure of cytosolic class II small heatshock proteins. Plant Physiol. 114, 1477-1485.

43. Fontaine, J. M., Sun, X., Benndorf, R. \& Welsh, M. J. (2005). Interactions of HSP22 (HSPB8) with HSP20, alphaB-crystallin, and HSPB3. Biochem. Biophys. Res. Commun. 337, 1006-1011.
44. Reddy, G. B., Kumar, P. A. \& Kumar, M. S. (2006). Chaperone-like activity and hydrophobicity of alphacrystallin. IUBMB Life, 58, 632-641.

45. Giese, K. C., Basha, E., Catague, B. Y. \& Vierling, E. (2005). Evidence for an essential function of the $\mathrm{N}$ terminus of a small heat-shock protein in vivo, independent of in vitro chaperone activity. Proc. Natl Acad. Sci. USA, 102, 18896-18901.

46. Boros, S., Kamps, B., Wunderink, L., de Bruijn, W., de Jong, W. W. \& Boelens, W. C. (2004). Transglutaminase catalyzes differential crosslinking of small heatshock proteins and amyloid-beta. FEBS Lett, 576, 57-62.

47. Hernandez, H. \& Robinson, C. V. (2007). Determining the stoichiometry and interactions of macromolecular assemblies from mass spectrometry. Nature Protoc. 2, 715-726.

48. Brown, P. H. \& Schuck, P. (2008). A new adaptive grid-size algorithm for the simulation of sedimentation velocity profiles in analytical ultracentrifugation. Comput. Phys. Commun. 178, 105-120.

49. Cole, J. L., Lary, J. W., Moody, P. \& Laue, T. M. (2008). Analytical ultracentrifugation: sedimentation velocity and sedimentation equilibrium. Methods Cell Biol. 84, 143-179. 